\title{
In vivo analgesic, anti-inflammatory potential in Swiss albino mice and in vitro thrombolytic activity of hydroalcoholic fruits extract from Daemonorops robusta Warb
}

\author{
Mir Muhammad Nasir Uddin ${ }^{1}$, Shahriar Ahmed ${ }^{1}$, Mohammad Shah Hafez Kabir ${ }^{2}$, Mohammad Sofiqur Rahman ${ }^{3}$, \\ Ramiz Ahmed Sultan ${ }^{1}$,Talha Bin Emran ${ }^{4,5,6^{*}}$ \\ ${ }^{1}$ Department of Pharmacy, University of Chittagong, Chittagong-4331, Bangladesh. \\ ${ }^{2}$ Department of Pharmacy, International Islamic University Chittagong, Chittagong-4203, Bangladesh. \\ ${ }^{3}$ Drug Management and Policy, Division of Pharmaceutical Sciences, Kakuma-machi, Kanazawa 920-1192, Japan. \\ ${ }^{4}$ Laboratory of Vaccinology and Applied Immunology, Kanazawa University School of Pharmacy, Kakuma-machi, Kanazawa 920-1192, Japan. \\ ${ }^{5}$ Department of Pharmacy, BGC Trust University Bangladesh, Chittagong-4000, Bangladesh. \\ ${ }^{6}$ Department of Biochemistry and Molecular Biology, University of Chittagong, Chittagong-4331, Bangladesh.
}

\section{ARTICLE INFO \\ Article history: \\ Received on: 09/08/2016 \\ Revised on: 20/09/2016 \\ Accepted on: 30/09/2016 \\ Available online: $31 / 01 / 2017$}

Key words:

Daemonorops robusta, Analgesic activity, Antiinflammatory activity,

Thrombolytic activity.

\begin{abstract}
Objectives: The analgesic, anti-inflammatory and thrombolytic potential of Daemonorops robusta Warb, a Bangladeshi tribal medicinal plant was studied for the first time. So our aim was to evaluate analgesic, antiinflammatory and thrombolytic activities of fruit extract of D. robusta.

Methods: Fresh fruits of plant were extracted with methanol and then subjected to preliminary phytochemical screening. Analgesic activity of the extract was performed against acetic acid induced writhing, hot plate and formalin induced test. Anti-inflammatory effect was evaluated using carrageenan induced paw edema in mice. An In Vitro thrombolytic model was used to check the clot lysis potential of the extract.

Results: Phytochemical screening showed the presence of alkaloid, carbohydrate, flavonoids, steroid, phlobatanin and saponin. The extract exhibited significant analgesic effect $(P<0.001)$ at dose-dependent manner. In addition, administration of glibenclamide, an ATP-sensitive $\mathrm{K}^{+}$channel antagonist partly reversed antinociceptive activity shown by the plant extract. It is observed that the anti-nociceptive activity of plant extract involves the NO-cGMP pathway. Besides, the anti-inflammatory activity of plant extract was significant $(P<0.001)$. In thrombolytic activity assay, a moderate percentage $(\%)$ of clot lysis was observed when compared to standard drug streptokinase.

Conclusion: Our findings suggest that the fruits of D. robusta possess significant analgesic and antiinflammatory activities. This plant also contains moderate thrombolytic potential.
\end{abstract}

\section{INTRODUCTION}

Pain as a type of Inflammation is suffered by almost everyone will probably throughout their lifetime (Kennedy, 2007). Inflammation is the defense response of body, characterized by redness, swelling, heat, pain, and loss in function

\footnotetext{
* Corresponding Author

Talha Bin Emran, Laboratory of Vaccinology and Applied Immunology, Kanazawa University School of Pharmacy, Kakuma-machi, Kanazawa, Japan.Email: talhabmb@gmail.com
}

to get rid of or limit the multiplication of an injurious agent (Riedel et al., 2015). It demands a cascade of events elicited by numerous stimuli that include infectious agents, ischemia, thermal and injuries, and antigen-antibody interaction (Khan et al., 2014). Cyclooxygenases (COX) or prostaglandin endo-peroxide synthases (PGHS) exists in two isoforms COX-1 and COX-2. They are classified as the key enzymes inside the synthesis of prostaglandins, the leading mediators of inflammation, pain and increased body temperature (hyperpyrexia) (Watson et al., 2000). 
While both isoform catalyze the same reactions, COX-1 is usually a constitutive enzyme in most cells-its activity is just not changed once the cell is grown. Conversely, COX-2 normally contained in insignificant amounts is inducible by cytokines, growth factor and other stimuli during the inflammation response. It is really assume that eicosanoids created by COX-1 get involved in physiologic functions for instance secretion of mucosa, haemostasis and repair of renal function, while those made by COX-2 contributes to inflammatory other pathological changes (Hinz and Brune, 2002; Kulkarni et al., 2000). Non-steroidal antiinflammatory drugs (NSAIDs) produce their therapeutic effects through inhibition of COX, the enzyme which enables prostaglandins. Non selective inhibition of COX iso-enzyme leads to not just beneficial therapeutic effects but in addition many detrimental effects. Beneficial effects are due to inhibition of COX-2 and detrimental effects result from inhibition of physiological COX-1 (Hinz and Brune, 2000; Urban, 2000a). Recently, a category of anti-inflammatory medications may be developed that primarily inhibits $\mathrm{COX}-2$ while sparing the enzymatic activity of COX-1 at therapeutic dosages. Two medications that predominantly inhibit only COX-2, rofecoxib and celecoxib, are available by prescription from the United State, India and Bangladesh (Everts et al., 2000; Hinz and Brune, 1999). The use of coxib drugs such as rofecoxib and valdecoxib were withdrawn from the market in 2004 and 2005, respectively, because of increased risk of heart attacks and strokes with long term use (Mason et al., 2007; Mason et al., 2006). Given the requirement for more potent and/or less toxic pain therapies, a lot of emphasis continues to be designed into identifying novel molecular targets that could form the basis achievable analgesics. Natural products, including medicinal plants, have been the key source for obtaining new drugs with therapeutic potential throughout history.

Approximately $50 \%$ of the drugs utilized are derived from natural products. According to the World Health Organization (WHO), poverty and not enough entry to powerful weight loss products leads from $65 \%$ to $80 \%$ of the world population in developing countries to critically be determined by plants for primary health care (Muccillo-Baisch et al., 2010; Parker et al., 2007).

In this context, at first, we designed our study to explore out the analgesic and anti-inflammatory activities of the methanolic extract of Daemonorops robusta Warb (MEDR). D. robusta (family: Arecaceae) is a common plant in Bangladesh and can be seen growing in tropics and subtropics area in Bangladesh. In Bangladesh, it is known as 'Bet pata' and in English as 'Palm'. It is found primarily in the tropics and sub-tropics of south eastern Asia.

The stems from the Daemonorops are harvest for his or her cores, which is used for from canes to furniture. The fruit of certain species, for example Daemonoropsdraco, creates a red resin referred to as "Dragon's blood". The seeds of species such as Daemonoropsmargaritae are harvested for the production of Buddhist prayer beads (Ghani, 2003). Since, there are insufficient studies on Daemonorops robusta fruits extract and studies must be conducted to determine its activity as medicinal plants. Hence this research work was designed to identify the chemical groups responsible for the traditional use, in addition to study the analgesic, anti-inflammatory and thrombolytic effect of Daemonorops robusta fruits.

\section{MATERIALS AND METHODS}

\section{Ethical Statement}

All experimental protocols were in compliance with Dhaka University Ethics Committee (approval number AE-DUEC 2012/118) on research in animals as well as internationally accepted principles for laboratory animal use and care (Zimmermann, 1983).

\section{Plant Material}

Fresh fruits of Daemonorops robusta (D. robusta) used in this study were collected from Chokoria, Cox's Bazar., Bangladesh during the month of February 2013 at the flowering stage. The plant samples were identified and authenticated by experts in the Bangladesh National Herbarium Mirpur, Dhaka. A voucher specimen (Accession No: DACB 328592) was deposited there for future reference.

The fruits of $D$. robustawere freed from any of the foreign materials. The plant parts, after cutting into small pieces, were sun dried for several days. The plant materials were then oven dried for $24 \mathrm{~h}$ for better grinding. The dried cutting pieces were pulverized by a mechanical grinder and stored into an airtight container.

\section{Extraction of the Plant Material and Sample Preparation}

Weighed (600 $\mathrm{g}$ of the dried and powdered) sample was soaked in $1500 \mathrm{~mL}$ of $99 \%$ methanol (Merck KGaA, Germany) in clean, sterilized and flat-bottomed glass container. Afterwards, it was sealed and maintained for 15 days accompanying occasional stirring and agitation. The complete mixture was then subjected to coarse filtration on a piece of clean, white sterilized cotton material and Whatman ${ }^{\circledR}$ filter paper. The extract was obtained by evaporation using rotary evaporator (Bibby RE-200, Sterilin Ltd., UK) at $4 \mathrm{rpm}$ and $65{ }^{\circ} \mathrm{C}$ temperature. It rendered a gummy concentrate of greenish black color.

The gummy concentrate was designated as crude extract, or ethanolic extract. Then the crude methanolic extract was dried by freeze drier and preserved at $+4{ }^{\circ} \mathrm{C}$ (yield $16.55 \% \mathrm{w} / \mathrm{w}$ ). The extracts and standard drug diclofenac were suspended in normal saline using $1.0 \%$ Tween-80.

\section{Chemicals and Reagents}

Diclofenac sodium was collected from Beximco Pharmaceuticals Ltd. Dhaka, Bangladesh. Carrageenan and acetic acid were purchased from Sigma-Aldrich, Germany. Streptokinase (SK) vial (Durakinase, DongkookPhama. Co. Ltd, South Korea) of 1500000 I.U was used for thrombolytic activity. 


\section{Experimental Animals}

For the experiment adult Swiss albino mice (BALB/c) weighing between (12-300) $\mathrm{g}$ of either sex were collected from animal house of International Centre for Diarrheal Disease and Research, Bangladesh (ICDDR, B), Dhaka. The animals were maintained under normal laboratory condition and kept in standard polypropylene cages at room temperature of $(30 \pm 2)^{\circ} \mathrm{C}$ and $60 \%$ to $65 \%$ relative humidity and provided with standard diet and water. Each group consists of five mice and to denote individual animal, they were marked as group I, II, III, IV for test samples at the doses of 100 and $200 \mathrm{mg} / \mathrm{kg}$ body weight and a control and positive control group was also maintained for every tests.

\section{Acute Toxicity Test}

Mice were divided into nine groups, each group consisting of six animals. Group 1 was given 1\% Tween-80 in normal saline ( $2 \mathrm{~mL}$ per $\mathrm{kg}$ body weight). The other eight groups (Groups 2-9) were administered, respectively, 100, 200, 300, 600, 800, 1000, 2000 and $3000 \mathrm{mg}$ of MEDR (Methanolic extract of $D$. robusta) per kg body weight. All animals were closely observed for the next $8 \mathrm{~h}$ to notice any behavioral changes or mortality and were kept under close observation for the next two weeks (Faisal et al., 2014).

\section{Phytochemical Screening}

The crude methanolic extract of D. robusta were qualitatively tested for the detection of carbohydrates, saponins, flavonoids, tannins, alkaloids, glycosides, glucosides, reducing sugars, proteins, and steroids following standard procedures (Ghani, 2003).

\section{IN VIVO ASSESSMENT}

\section{Analgesic Activity \\ Formalin-Induced Nociception}

Animals received $20 \mu \mathrm{L}$ of $2.5 \%$ formalin solution (7\% formaldehyde) made up in saline and injected intra-planetary in the ventral surface of the right hand paw. Animals were observed from 0-5 min (neurogenic phase) and 15-30 min inflammatory phase and the time spent licking the injected paw was recorded as indicative of nociception. The animals received MEDR at 100 and $200 \mathrm{mg} / \mathrm{kg} 1 \mathrm{~h}$ before, with basis of a previous time response curve. Positive control group received standard drug diclofenac sodium at the dose of $10 \mathrm{mg} / \mathrm{kg}$ body weight (Santos and Calixto, 1997; Santos et al., 2000).

\section{Hot Plate Method}

The paws of mice are very sensitive to temperature at (55 $\pm 0.5)^{\circ} \mathrm{C}$, which are not damaging to the skin. The animals were placed on Eddy's hot plate kept at a temperature of $(55 \pm 0.5)^{\circ} \mathrm{C}$. A cut off period of $30 \mathrm{sec}$ (Franzotti et al., 2000), was observed to avoid damage to the paw. Reaction time was recorded when animals licked their fore or hind paws, or jumped at $0,30,60$ and $90,120,180$ and 240 min after oral administration of the samples
(Momin et al., 2014). The animals of test groups received test samples at the doses of 100 and $200 \mathrm{mg} / \mathrm{kg}$ body weight. Positive control group received standard drug diclofenac sodium at the dose of $10 \mathrm{mg} / \mathrm{kg}$ body weight and saline water. A cut off period of 20 s was maintained to avoid paw tissue damage. The results of the hot plate test are expressed as a percentage of the maximal possible effect (\%MPE), which was calculated using following formula:

$\% \mathrm{MPE}=[($ Post drug latency - pre drug latency $) /($ Cut off period - pre drug latency) $] \times 100$

\section{Acetic Acid-Induced Writhing Test}

The anti-nociceptive activity of the extract was studied using acetic acid-induced writhing model in mice (Süleyman et al., 1999). The animals were divided into control, positive control and test groups with six mice in each group. The animals of test groups received test samples at the doses of 100 and $200 \mathrm{mg} / \mathrm{kg}$ body weight. Positive control group received standard drug diclofenac sodium at the dose of $10 \mathrm{mg} / \mathrm{kg}$ body weight. Test samples were administered orally $30 \mathrm{~min}$ before intra-peritoneal administration of $0.6 \%$ acetic acid but diclofenac sodium was administered 15 min before injection of acetic acid. After an interval of $5 \mathrm{~min}$, the mice were observed for specific contraction of body referred to as 'writhing' for the next $30 \mathrm{~min}$.

\section{Involvement of Cyclic Guanosine Monophosphate (Cgmp) Pathway}

To verify the possible involvement of cGMP in the antinociceptive action caused by MEDR, the mice were pre-treated with methylene blue $(20 \mathrm{mg} / \mathrm{kg})$, a non-specific inhibitor of NO/guanylylcyclase, intraperitonially $15 \mathrm{~min}$ before administration of MEDR. Then the nociceptive responses against $0.6 \%$ acetic acid injection were observed for $30 \mathrm{~min}$, starting from 5 min post injection. The numbers of abdominal writhing were counted as indication of pain behaviour(Abacioglu et al., 2000; Perimal et al., 2011).

\section{Involvement of Atp-Sensitive $\mathrm{K}^{+}$Channel Pathway}

Possible contribution of $\mathrm{K}^{+}$channel in the antinociceptive effect of MEDR was evaluated by established method (Mohamad et al., 2011; Perimal et al., 2011). The mice were pretreated with glibenclamide $(10 \mathrm{mg} / \mathrm{kg})$, an ATP-sensitive $\mathrm{K}^{+}$ channel inhibitor, intraperitoneally $15 \mathrm{~min}$ before administration of either vehicle or MEDR. The mice were challenged with i. p. injection of $0.6 \%$ acetic acid, 30 min post-treatment. Following the injection of acetic acid, the animals were immediately placed in a chamber and the number of writhing was recorded for $30 \mathrm{~min}$, starting from 5 min post injection.

\section{Anti-Inflammatory Activity Carrageenan-Induced Paw Edema}

The mice were divided into four groups $(n=4)$. The different groups were treated orally with $(100$ and $200 \mathrm{mg} / \mathrm{kg} \mathrm{b}$. w.), diclofenac sodium (10 mg/kg b. w.), and vehicle control 
$(0.9 \% \mathrm{NaCl}, 5 \mathrm{~mL} / \mathrm{kg}$ b. w.). The administration of extract and drugs was $30 \mathrm{~min}$ prior to injection of $0.1 \mathrm{~mL}$ of $1 \%$ freshly prepared suspension of carrageenan in normal saline in the right hind paw sub plantar of each rat. The paw volume was MEDR used initially and then at 1/2,1, 2, 3, 4 and $4 \mathrm{~h}$ after the carrageenan injection by using plethysmometer(Winter and Porter, 1957). The anti-inflammatory effect of MEDR was calculated by the following equation:

Anti-inflammatory activity $(\%)=(1-\mathrm{D} / \mathrm{C}) \times 100$

Where, $\mathrm{D}$ represents the percentage difference in paw volume after the administration of drugs to the rats and $\mathrm{C}$ represents the percentage difference of volume in the control groups (Süleyman et al., 1999).

\section{In Vitro Assessment \\ Blood Specimen}

Whole blood $(1.5 \mathrm{~mL})$ was drawn from healthy human volunteers $(n=10)$ without a history of oral contraceptive or anticoagulant therapy using a protocol approved by the Institutional Ethics Committee of Chittagong University, Faculty of medicine. An earlier consent, approval number HET-CU2011/1, was taken from the faculty of medicine, University of Chittagong, for collection of blood samples from Human volunteers. Blood collection and preservation were conducted by Dr. M Rafiqur Rahman (Pathologist, Faculty of Medicine, University of Chittagong). A $500 \mu \mathrm{L}$ of blood was transferred to each of the three previously weighed microcentrifuge tubes to form clots.

\section{Statement on Informed Consent of the Donors}

The volunteer donors were supplied a consent form which informed the title of the scientific study, name and detail contact of investigators as well as aim of the investigation. Description in the research mentioning step-by-step brief of the proposed research, inclusion and exclusion criteria of the donors, whether donors will have any therapy or otherwise, volume of blood to become taken, possible discomfort from the puncture sites, time important for the blood sampling. Explanation was developed on if future use of the research data beyond the latest study is predicted, whether this is the focus group if so the Principal Investigator should put an activity in place where the researchers caution people regarding the limit on confidentiality. Usage of Research Information regarding who does have access to the collected sample, information regarding retention of sample and schedules for his or her disposal were also detailed. It absolutely was indicated towards consent form the volunteers might not donate blood anytime. Donor whether could withdraw his sample data was disclosed. The sample was restricted with the individual study not for future research projects was presented within the consent form. Potential harm, injuries, discomforts or inconvenience regarding donors within this study was added as informed consent statement. If there was known harm to the donors, the opportunity harm, current knowledge concerning the possibility of the occurrence of the injury, clinical fact that the injury; and any relevant knowledge regarding the probability of reversibility; as an example the potential for bruising or swelling while giving blood, or another (a) discomforts at the site where blood is drawn understanding that there might be minimal potential for infection, and this these discomforts were brief and transient were also added. Potential benefits of the donors, indirectly, nevertheless the society in the main or those that have an identical condition might take advantage of the connection between these studies was explained. Treatment alternative and prospects for the study was described. Confidentiality statement was within the consent form the way that "confidentiality are going to be respected and no information that discloses the identity in the participant will be released or published without consent unless essential to law of states. The legal obligation carries a amount of circumstances, like suspected child abuse and infectious disease, expression of suicidal ideas where research documents are ordered to be manufactured by a court of justice and where researchers are obliged to report to the right authorities. In those rare instances where it won't be possible to assure complete confidentiality", the limits for this obligation were carefully explained. Reimbursement issue seemed to be mentioned regardless of if the donors or their parents could be offered money for reasonable out-of-pocket expenses e.g., transportation costs, meals, etc. Finally detail contact (Name, area code and phone number) of investigators was provided in case of any questions of the donors about this study. The consent form was concluded with major questions on above disclosures in Yes/NO form followed by the signature (with date) of the donor.

\section{CLOT LYSIS}

Experiments for clot lysis were carried as reported earlier (Prasad et al., 2006). Briefly, four ml venous blood drawn from the healthy volunteers was distributed in three different pre weighed sterile microcentrifuge tube $(0.5 \mathrm{~mL} /$ tube $)$ and incubated at $37{ }^{\circ} \mathrm{C}$ for $45 \mathrm{~min}$. After clot formation, serum was completely removed without disturbing the clot and each tube having clot was again weighed to determine the clot weight (clot weight $=$ weight of clot containing tube -weight of tube alone). To each microcentrifuge tube containing pre-weighed clot, $100 \mu \mathrm{L}$ of were added separately. As a positive control, $100 \mu \mathrm{L}$ of SK and as a negative non-thrombolytic control, $100 \mu \mathrm{L}$ of distilled water were separately added to the control tubes numbered. All the tubes were then incubated at $37^{\circ} \mathrm{C}$ for $90 \mathrm{~min}$ and observed for clot lysis. After incubation, fluid released was removed and tubes were again weighed to observe the difference in weight after clot disruption. Difference obtained in weight taken before and after clot lysis was expressed as percentage of clot lysis. The experiment was repeated with the blood samples of the 10 volunteers.

\section{Statistical Analysis}

Statistical analysis for animal experiment was carried out using One-way ANOVA followed by Dunnet's multiple comparisons. The results obtained were compared with the control group. $\mathrm{P}<0.001$ was considered to be statistically significant. 


\section{RESULTS}

\section{Acute toxicity test}

The present study demonstrated that oral administration of the MEDR at the various doses did not show any mortality, behavioral changes (sedation, excitability) or allergic manifestations during the 8 hours observation period after administration.

\section{Preliminary phytochemical group tests}

Phytochemical screening of $D$. robustafruits extract under this study explored the presence of medicinally active secondary metabolites alkaloid, carbohydrates, glycoside, cardiac glycoside, flavonoids, steroid, phlobatanins and saponins. This investigation also indicated the absence of glycoside, cardiac glycoside, terpenoids and tannin. These findings with their corresponding results are summarized in Table 1.

\section{Formalin-induced nociception}

Table 2 Shows the result of statistical evaluation of the effect of MEDR on formalin induced writhing in mice. The results of the test showed that MEDR at a dose of $200 \mathrm{mg} / \mathrm{kg}$ exhibited highly significant $(\mathrm{P}<0.001)$ inhibition of writhing reflex by $61.94 \%$ while the standard drug diclofenac inhibition was found to be 54.77 at a dose of $10 \mathrm{mg} / \mathrm{kg}$ body weight. The analgesic activity of the extract was significant in comparison with control animals.
The extract, at dose of $200 \mathrm{mg} / \mathrm{kg}$ showed significant decrease in Formalin induced writhing reflex of mice.

\section{Hot plate test}

Table 3 shows the results of the hot plate test. MEDR increased the latency time at doses of 100 and $200 \mathrm{mg} / \mathrm{kg}$ after 60, 120, 180 and 240 minutes, respectively. The extract, at dose of $200 \mathrm{mg} / \mathrm{kg}$ showed the increasing of maximal possible effect from $40.58 \%$ at $30 \mathrm{~min}$ to $73.57 \%$ at $3 \mathrm{~h}$ which is more significant comparing to other doses.

\section{Acetic acid induced test}

The intraperitoneal administration of MEDR (100 and $200 \mathrm{mg} / \mathrm{kg}$ ) had a dose-dependent antinociceptive effect and significantly decreased the number of writhing movements induced by the i.p. administration of the acetic acid compared with the control group $(\mathrm{P}<0.01)$. The percentages of inhibition of MEDR were $26 \%$ and $17.8 \%$ at dose of $100,200 \mathrm{mg} / \mathrm{kg}$, respectively(Table 4). The extracts have effectively reduced the number of abdominal muscle contractions induced by $0.6 \%$ acetic acid solution. The extracts produced significant inhibition of writhing induced by acetic acid. The inhibition was used dosedependent. The results are presented in Table 4. However, MEDR at a dose of $200 \mathrm{mg} / \mathrm{kg}$ has produced higher inhibition values comparatively to the positive control of diclofenac sodium.

Table 1: Observation and results of phytochemical screening.

\begin{tabular}{|c|c|c|c|}
\hline $\begin{array}{l}\text { Secondary } \\
\text { metabolite }\end{array}$ & Name of the test & Observation & Result \\
\hline \multirow{3}{*}{ Alkaloids } & 1. Mayer's test & White or creamy white precipitate & ++ \\
\hline & 2. Hager's test & Yellow crystalline precipitate & ++ \\
\hline & 3.Wagner's test & Brown or deep brown precipitate & ++ \\
\hline Glycosides & General test & No yellow color & -- \\
\hline \multirow{2}{*}{ Cardiac glycosides } & 1. Legal's test & No pink or red color & -- \\
\hline & 2. Baljet's test & No yellow orange color & -- \\
\hline Terpenoids & Salkowsky test & No reddish colouration & -- \\
\hline \multirow{2}{*}{ Carbohydrates } & 1.Molisch Test & Red-violet layer at the interface between the acid (bottom) and aqueous (upper) layers & ++ \\
\hline & 2.Fehling's Test & Red precipitate & ++ \\
\hline \multirow{2}{*}{ Flavonoids } & 1. General test & A yellow colouration & ++ \\
\hline & 2. Specific test & Orange to red color & ++ \\
\hline Steroids & Libermann-Burchard's test & Greenish color & ++ \\
\hline Tannins & $\mathrm{FeCl}_{3}$ test & No brownish green color & -- \\
\hline Phlobatanins & General test & Red precipitate formation & ++ \\
\hline Saponins & Frothing test & Change is observed & ++ \\
\hline
\end{tabular}

N.B. “++" stands for the presence and "--" indicates the absence of secondary metabolites

Table 2: Effect of methanolic extract of the D. robusta (MEDR), control and diclofenac sodium (Diclofenac $10 \mathrm{mg} / \mathrm{kg}$ ) on formalin induced writhing effect in mice.

\begin{tabular}{|c|c|c|c|c|c|}
\hline Groups & $\begin{array}{c}\text { Dose } \mathrm{mg} / \mathrm{kg} \\
\text { BW }\end{array}$ & $\begin{array}{c}\text { Mean } \pm \text { SEM } \\
\text { (\% Writting) } \\
\text { 1st phase }(0-5 \mathrm{~min})\end{array}$ & $\begin{array}{c}\text { \%inhibition } \\
1 \text { st phase }(0-5 \text { min) }\end{array}$ & $\begin{array}{c}\text { Mean } \pm \text { SEM } \\
(\% \text { Writting }) \\
\text { last phase }(20-30 \mathrm{~min})\end{array}$ & $\begin{array}{l}\text { \%inhibition } \\
\text { last phase } \\
\text { (20-30min) }\end{array}$ \\
\hline Control & - & $14.33 \pm 1.33$ & - & $22.3 \pm 1.838$ & - \\
\hline Diclofenac sodium & 10 & $14.0 \pm 1.0$ & $2.30 \%$ & $10.167 \pm 1.47 * * *$ & $54.47 \%$ \\
\hline MEDR & 100 & $13.33 \pm 0.761$ & $6.978 \%$ & $12.0 \pm 2.66 * * *$ & $46.27 \%$ \\
\hline MEDR & 200 & $8.83 \pm 1.167 * * *$ & $38.39 \%$ & $8.5 \pm 1.78 * * *$ & $61.94 \%$ \\
\hline
\end{tabular}


Table 3: Effect of methanolic extract of the D. robusta (MEDR), control and diclofenac sodium (Diclofenac $10 \mathrm{mg} / \mathrm{kg}$ ) on thermally induced pain stimulus in mice.

\begin{tabular}{|c|c|c|c|c|c|c|}
\hline Group & 0 min & $30 \mathrm{~min}$ & $1 \mathrm{hr}$ & $2 \mathrm{hr}$ & $3 \mathrm{hr}$ & $4 \mathrm{hr}$ \\
\hline Control & $8.28 \pm 1.557$ & $8.66 \pm 2.131$ & $8.56 \pm 0.745$ & $7.96 \pm 0.332$ & $8.76 \pm 0.950$ & $8.04 \pm 0.899$ \\
\hline Positive Control & $\begin{array}{c}10.46 \pm 0.953 \\
(22.00)\end{array}$ & $\begin{array}{c}9.48 \pm 1.572 \\
(13.99)\end{array}$ & $\begin{array}{c}9.70 \pm 0.610 \\
(15.78)\end{array}$ & $\begin{array}{c}9.94 \pm 0.978 \\
(17.74)\end{array}$ & $\begin{array}{c}9.94 \pm 0.297 \\
(17.74)\end{array}$ & $\begin{array}{c}9.96 \pm 0.888 \\
(17.90)\end{array}$ \\
\hline Extract $100 \mathrm{mg} / \mathrm{kg}$ & $\begin{array}{c}9.18 \pm 1.589 \\
(8.85)\end{array}$ & $\begin{array}{c}14.18 \pm 2.402 \\
(50.96)\end{array}$ & $\begin{array}{c}13.32 \pm 2.203 * \\
(43.72)\end{array}$ & $\begin{array}{c}13.90 \pm 2.293^{* * *} \\
(48.60)\end{array}$ & $\begin{array}{c}14.14 \pm 2.032 * \\
(50.63)\end{array}$ & $\begin{array}{c}13.34 \pm 2.131 * \\
(43.89)\end{array}$ \\
\hline Extract $200 \mathrm{mg} / \mathrm{kg}$ & $\begin{array}{c}8.94 \pm 0.786 \\
(13.53)\end{array}$ & $\begin{array}{c}12.4 \pm 1.279 \\
(40.58)\end{array}$ & $\begin{array}{c}13.46 \pm 0.693 * \\
(48.87)\end{array}$ & $\begin{array}{c}15.12 \pm 0.397^{* * *} \\
(61.85)\end{array}$ & $\begin{array}{c}16.62 \pm 0.392 * * * \\
(73.57)\end{array}$ & $\begin{array}{c}13.06 \pm 0.773 * \\
(45.74)\end{array}$ \\
\hline
\end{tabular}

Table 4: Effect of methanolic extract of the D. robusta (MEDR), control and diclofenac sodium (Diclofenac $10 \mathrm{mg} / \mathrm{kg}$ ) on acetic acid induced writhing test.

\begin{tabular}{ccc}
\hline Group & Dose & No. of writhing \\
\hline Control & - & $54.4 \pm 8.5564$ \\
Diclofenac sodium & $10 \mathrm{mg} / \mathrm{kg}$ & $23.4 \pm 5.8365 * *$ \\
MEDR & $100 \mathrm{mg} / \mathrm{kg}$ & $26 \pm 2.6832^{*}$ \\
MEDR & $200 \mathrm{mg} / \mathrm{kg}$ & $17.8 \pm 5.774 * *$ \\
\hline SEM & . & \\
\hline
\end{tabular}

$\mathrm{SEM}=$ standard error of mean, $\mathrm{n}=6$ where, $\mathrm{n}$ is the number of mice. Values in the figure are expressed as mean \pm SEM, $* \mathrm{p}<0.05, * * \mathrm{p}<0.01, * * * \mathrm{p}<0.001$ significantly different in comparison with control. The data was analyzed by ANOVA followed by Dunnett's test.

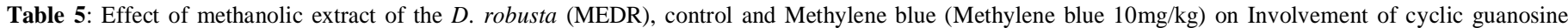
monophosphate (cGMP) pathway.

\begin{tabular}{|c|c|c|c|c|}
\hline Group & Treatment & Dose & No. of writhing & Percent inhibition \\
\hline Control & $1 \%$ Tween-80 in water & $01 \mathrm{~mL} / \mathrm{mouse}$ & $68.54 \pm 2.534$ & - \\
\hline Standard & Methylene Blue & $10 \mathrm{mg} / \mathrm{kg}, \mathrm{i}, \mathrm{p}$ & $54.25 \pm 3.23$ & 20.85 \\
\hline Test & MEDR & $100 \mathrm{mg} / \mathrm{kg}$, p.o & $34.95 \pm 2.35 * * *$ & 49.00 \\
\hline Test & MEDR & $200 \mathrm{mg} / \mathrm{kg}$ & $19.15 \pm 0.30 * * *$ & 72.06 \\
\hline
\end{tabular}

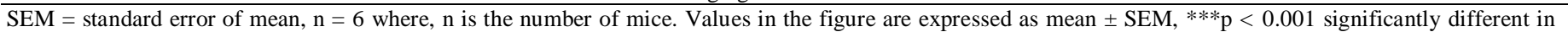
comparison with control. The data was analyzed by ANOVA followed by Dunnett's test.

Table 6: Effect of methanolic extract of the D. robusta (MEDR), control and Glibenclamide (Glibenclamide 10mg/kg) on Involvement of ATP-sensitive K+ channel pathway.

\begin{tabular}{ccccc}
\hline Group & Treatment & Dose & No of writhing & Percent inhibition \\
\hline Control & 1\% Tween-80 in water & $1 \mathrm{~mL} / \mathrm{mouse}$ & $74.55 \pm 1.87$ & - \\
Standard & Glibenclamide & $10 \mathrm{mg} / \mathrm{kg}, \mathrm{i}, \mathrm{p}$ & $77.76 \pm 2.58$ & - \\
Test & MEDR & $100 \mathrm{mg} / \mathrm{kg}, \mathrm{p} . \mathrm{o}$ & $40.89 \pm 2.89^{* * *}$ & 45.15 \\
Test & MEDR & $200 \mathrm{mg} / \mathrm{kg}$ & $23.85 \pm 1.88^{* * *}$ & 74.31 \\
\hline
\end{tabular}

$\mathrm{SEM}=$ standard error of mean, $\mathrm{n}=6$ where, $\mathrm{n}$ is the number of mice. Values in the figure are expressed as mean \pm SEM, $* * * p<0.001$ significantly different in comparison with control. The data was analyzed by ANOVA followed by Dunnett's test.

\section{Involvement of cyclic guanosine monophosphate (cGMP) pathway}

The present study looked at the effects of 100 and 200 $\mathrm{mg} / \mathrm{kg}$ MEDR and methylene blue $(20 \mathrm{mg} / \mathrm{kg})$ treatments. MEDR and methylene blue (MB) administration alone significantly inhibited acetic acid induced abdominal writhing (Table 5). Given together, MB significantly $(\mathrm{P}<0.001)$ enhanced MEDR $(100$ and $200 \mathrm{mg} / \mathrm{kg}$ ) induced anti-nociception compared to the treatment of both MEDR and MB alone.

\section{Involvement of ATP-sensitive $\mathrm{K}^{+}$channel pathway}

The present study looked at the effects of 100 and 200 $\mathrm{mg} / \mathrm{kg}$ MEDR and glibenclemide $(10 \mathrm{mg} / \mathrm{kg})$ treatments. It was found that glibenclamide $(10 \mathrm{mg} / \mathrm{kg})$ administration alone did not alter abdominal writhing count when assessed through the injection of $0.6 \%$ acetic acid (Table 6). When given together antinociceptive activity of MEDR (100 mg/kg, $200 \mathrm{mg} / \mathrm{kg}$ ) was markedly decreased by glibenclamide.

\section{Carrageenan induced paw edema}

The anti-inflammatory activity at test doses (100 and 200 $\mathrm{mg} / \mathrm{kg}$ i. p.) of MEDR is presented in Table 7 with the average volume of the paw edema. The percent protection of inflammation is presented in Table 8 .

The injection of the carrageenan in paw created an inflammatory edema which increased gradually. The MEDR at the dose of $200 \mathrm{mg} / \mathrm{kg}$ injection of carrageenan and was maintained all along the experiment with a maximum effect of $\%$. The extract $(100 \mathrm{mg} / \mathrm{kg})$ also induced significant $(\mathrm{P}<0.001)$ antiinflammatory effect and the anti-inflammatory effect of diclofenac sodium $(10 \mathrm{mg} / \mathrm{kg})$ was less than that of the extract as presented in Table 8 . 
Table 7: Effect of methanolic extract of the D. robusta (MEDR), control and diclofenac sodium (Diclofenac $10 \mathrm{mg} / \mathrm{kg}$ ) on carrageenan-induced paw edema test.

\begin{tabular}{|c|c|c|c|c|c|c|c|}
\hline Group & $0 \mathrm{~min}$ & $30 \mathrm{~min}$ & $60 \mathrm{~min}$ & $120 \mathrm{~min}$ & $180 \mathrm{~min}$ & $240 \mathrm{~min}$ & $360 \mathrm{~min}$ \\
\hline Control & $0.8075 \pm 0.0453$ & $1.195 \pm 0.1133$ & $1.472 \pm 0.0342$ & $1.485 \pm 0.031$ & $1.577 \pm 0.0656$ & $1.7 \pm 0.0653$ & $1.571 \pm 0.0865$ \\
\hline $\begin{array}{l}\text { Diclofenac sodium } \\
10 \mathrm{mg} / \mathrm{kg}\end{array}$ & $0.795 \pm 0$ & $1.027 \pm$ & $1.052+$ & $7 \pm 0$ & $05+0$ & $13+$ & $4 *$ \\
\hline MEDR $100 \mathrm{mg} / \mathrm{kg}$ & $0.92 \pm 0.0537$ & 967 & $9^{* *}$ & ** & $1.007 \pm$ & 1.47 & $1.275 \pm$ \\
\hline MEDR $200 \mathrm{mg} / \mathrm{kg}$ & $0.7525 \pm 0.01315$ & $0.983 \pm 0.0463$ & $1.158 \pm 0.0335^{*}$ & $1.191 \pm 0.0483^{*}$ & $1.047 \pm 0.0413 * * *$ & $1.515 \pm 0.0857$ & $1.325 \pm 0.0796$ \\
\hline
\end{tabular}

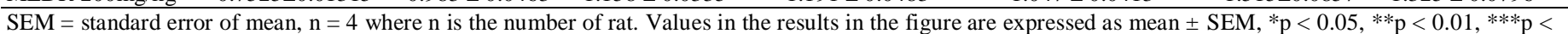

0.001 significantly different in comparison with control. The data was analyzed by ANOVA followed by Dunnett's test.

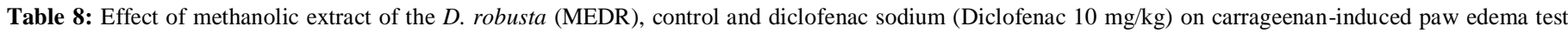
(Percent of Inhibition).

\begin{tabular}{|c|c|c|c|c|c|c|}
\hline \multirow[t]{2}{*}{ Group } & \multicolumn{6}{|c|}{ Percent of Inhibition } \\
\hline & 30 min & $60 \mathrm{~min}$ & $120 \mathrm{~min}$ & $180 \mathrm{~min}$ & $240 \mathrm{~min}$ & $360 \mathrm{~min}$ \\
\hline Diclofenac sodium $(10 \mathrm{mg} / \mathrm{kg})$ & 41.18 & 58.63 & 57.63 & 73.12 & 43.42 & 49.5 \\
\hline MEDR $(100 \mathrm{mg} / \mathrm{kg})$ & 63.4 & 73.88 & 70.27 & 89.5 & 38.38 & 54.1 \\
\hline MEDR $(200 \mathrm{mg} / \mathrm{kg})$ & 40.52 & 35.1 & 34.95 & 62.3 & 15.12 & 25.58 \\
\hline
\end{tabular}

Table 9: Thrombolytic activity of methanol extract of D. robusta (MEDR).

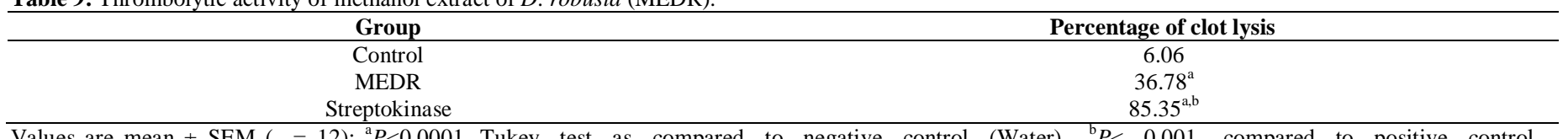

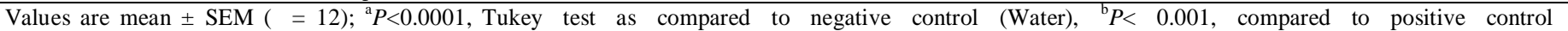

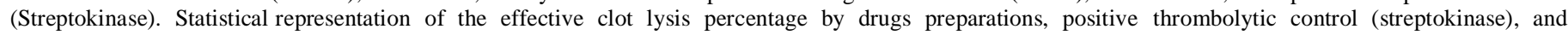
negative control (sterile distilled water) processed by Tukey test by using SPSS for windows.

\section{Thrombolytic activity test}

The effective clot lysis percentage by four different extracts of the plant, positive thrombolytic control (Streptokinase) and negative control (water) is tabulated in Table 9. It is evident that the percentage of clot lysis was $(85.35 \pm$ $0.35) \%$ when $100 \mu \mathrm{l}$ of streptokinase (30,000 I.U.) was used as a positive control, while in case of negative control (water) the percentage of clot lysis was negligible $(6.06 \pm 0.85) \%$. The crude methanolic extracts showed $(36.78 \pm 0.80) \%$ clot lysis which was much higher than the negative control (water) (Table 9).

\section{DISCUSSION}

Herbal preparations are used since ancient times to maintain health and regain healthy state of mind. Advances in phytochemistry and identification of plant compounds, which are effective in curing certain diseases have renewed the interest in herbal medicines. About $30 \%$ of the pharmaceuticals are prepared from plants worldwide (Khan et al., 1979). The phytochemical composition of herbal products is highly variable (Uddin et al., 2014). Phytochemical analysis conducted on the plant extracts revealed the presence of constituents which are known to exhibit medicinal as well as physiological activities as discussed by Sofowora(Ghani, 2003). In our study, the phytochemical screening of the crude extracts of $D$. robusta revealed the presence of various phytochemicals like alkaloid, carbohydrate, flavonoid, steroid, phlobatanin and saponin. Different polyphenolic compounds like flavonoids, phenolic acids and tannins show multiple biological effects (Uddin et al., 2014). The formalin test is an important model of analgesic which is better related with clinical pain (Ghannadi et al., 2005; Tjølsen et al., 1992). Formalin-induced nociception is biphasic in which first phase involves direct stimulation of sensory nerve fibres representing neuropathic pain and second phase involves inflammatory pain mediated by prostaglandin, serotonin, histamine, bradikinin and cytokines such as IL-1 $\beta$, IL-6, TNF- $\alpha$, eicosanoids and NO (Murray et al., 1988; Watkins et al., 1997). In our study, MEDR produced antinociception in both phases of the formalin test, but the effect was more significant in the inflammatory phase (Table 2). Phytochemicals may be responsible for the observed analgesic activity (Zulfiker et al., 2010). In addition, the anti-nociceptive effect of MEDR on the later phase recommended the antinociceptive potential could involve the anti-inflammatory property.

The hot plate is a useful method for the evaluation of centrally acting analgesics which are known to promote the pain threshold of mice towards heat (Bighettiet al., 1999). To determine the useful involvement of the opioid receptors in the action of narcotic drugs or other analgesic agents that give effect in this pathway this test is extremely supportive (Hiruma-Lima et al., 2000). The findings of our study indicate that MEDR at all doses, particularly at $200 \mathrm{mg} / \mathrm{kg}$ significantly prolonged the latency period $(\mathrm{P}<0.001)$. The ability of the extract to prolong the reaction latency suggests that the extract is endowed with central analgesic activity.

The peripheral analgesic effect may be mediated through the inhibition of cyclooxygenases and/or lipoxygenases and other inflammatory mediators (Urban, 2000b). According to Adeyemi et 
al. (Adeyemi et al., 2008) and Zhang et al. (Zhang et al., 2009), acetic acid-induced writhing is a highly sensitive and useful test for analgesic drug development especially peripherally acting analgesics. Acetic acid induces pain by liberating endogenous substances such as bradykinin, serotonin, histamine, substance $\mathrm{P}$ which in turn excite the pain nerve endings (Lu et al., 2007). In our observation, MEDR significantly $(\mathrm{P}<0.001)$ reduced the abdominal constriction response induced by the acetic acid in a dose-dependent manner.

Our present study also considered the probable contribution of cGMP pathway on the analgesic or antinociceptive activity of MEDR. Physiological functions such as analgesia are greatly influenced by the cellular level of cGMP maintained by the action of soluble guanylylcyclase (sGC) mediated by nitric oxide (NO) (Abacioglu et al., 2000). It has been described that the function of cGMP on the ion channel depends on the activation of protein kinases and phosphodiesterases(Xu et al., 1995). The activation or deactivation of nociresponsive neurons are regulated by intracellular cGMP. To study the possible involvement of cGMP in MEDR induced antinociception, a guanylylcyclise and/or NO inhibitor named methylene blue (MB) was administered before inducing nociception with acetic acid injection. This pretreatment with MB significantly reduced the nociception caused by acetic acid and at the same time also promoted the antinociceptive activity exerted by MEDR. It has been postulated that MB induces antinociceptive effect by inhibiting peripheral sGC and NO. As pre-treatment with MB and subsequent administration of MEDR at all doses increased antinociceptive activity in acetic acid induced writhing model in mice than the groups where only MEDR were administered, it is quite clear that the antinociceptive action of MEDR involves the NO-cGMP pathway(Abacioglu et al., 2000; $\mathrm{Xu}$ et al., 1995). Our present study also demonstrated that glibenclamide, an ATP-sensitive $\mathrm{K}+$ channel antagonist, partly reversed the antinociceptive activity shown by MEDR. The results of this study, therefore, might indicate the involvement of ATP sensitive $\mathrm{K}+$ channel opening and subsequent efflux of $\mathrm{K}+$ ion and membrane repolarization and/or hyperpolarization by MEDR which reduces the membrane excitability (Lawson, 1996).

Carageenan-induced paw edema has been commonly used as an experimental animal model for acute inflammation and is believed to be biphasic in which the early phase (1-2 $h)$ of the carageenan model is mainly mediated by histamine, serotonin, and increased synthesis of prostaglandins in the damaged tissue surroundings and the late phase is sustained by prostaglandin release and mediated by bradikinin, leukotrienenes, polymorphonuclear cells, and prostaglandins produced by tissue macrophase(Gupta et al., 2006; Gupta et al., 1993). The result of pre-treatment of MEDR demonstrated that the extract (100 and $200 \mathrm{mg} / \mathrm{kg}$ i. p.) is effective in the first or early phase of inflammation which is due to release of histamine and serotonin primarily. The anti-inflammatory effect of the extract remains significant up to $3 \mathrm{rd} \mathrm{h}$ of the experiment. MEDR showed significant activity against histamine induce edema in both phases.
Thrombosis or blood clot formation is often a critical event where the damaged elements of the endothelial cell surface or blood vessel are blocked from the deposition of platelets, tissue factor and fibrin. Platelets play a major role in the clot formation process as the process of thrombosis is initiated when the activated platelets form platelets to platelets bonds (Furie and Furie, 2008). These activated platelets further bind to the leucocytes and bring them into a complex process of plaque formation and growth. It is the thrombolytic agents that lyse clot by disrupting the fibrinogen and fibrin contained in a clot. Plasmin is one of the natural anti-thrombotic agents. The cell surface bound plasminogen is easily activated to plasmin which ultimately leads to fibrinolysis (Pantzar et al., 1998). Streptokinase (a bacterial plasminogen activator), a popular clot buster, is effective at converting additional plasminogen to plasmin (Rahman et al., 2013). But this drug has several side effects like bleeding and embolism which produce further complications. However to overcome these complications, many researchers are trying to discover new sources of herbs or natural foods having antithrombotic effect with minimal adverse effect (Rahman et al., 2013). As part of that searching we also attempted to find whether the MDER possess thrombolytic activity or not. Once we compared the result of positive control (streptokinase) with that of negative control (water), we observed that there was insignificant amount of clot disruption when water was added to the clot. It was reported that phytochemicals like saponin and alkaloids are responsible for thrombolytic activity (Bhowmick $e t$ al., 2014). As the MEDR possesses saponin and alkaloids as discussed above, therefore the possibility of the presence of these phytoconstituents in the crude extract may be the probable reason of demonstrating the thrombolytic potential.

\section{CONCLUSION}

It is concluded that MEDR (Methanolic extract of $D$. robusta)has marked analgesic and anti-inflammatory activities in various animal models and these results support the traditional use of this plant in different painful conditions and can also be used as a thrombolytic agent. Therefore, it may presage further studies to better understand the mechanism of such actions scientifically.

\begin{abstract}
Abbreviations: MEDR=Methanolic extract of Daemonorops robusta $; \mathrm{h}=$ Hour; $\min =$ Minutes; $\mathrm{kg}=$ Kilogram; $\mathrm{g}=\mathrm{Gram} ; \mu \mathrm{g}=$ Microgram; $\mu \mathrm{L}=$ Microlitre $\mathrm{L}=$ Liter; $\mathrm{mL}=$ Millilitre; $\mathrm{mg} / \mathrm{kg}=$ Milligram per kilogram; \%= Percent; $n=$ the number of mice; b.w = body weight; et al. $=$ et alliori (and others); SEM= Standard Error Mean;;i. p.= intra-peritoneal; $\mathrm{MB}=$ methylene blue; $\mathrm{NO}=$ Nitric oxide; cGMP = cyclic guanosine monophosphate; $\mathrm{sGC}=$ soluble guanylylcyclase
\end{abstract}

\section{Financial support and sponsorship: Nil.}

Conflict of Interests: There are no conflicts of interest. 


\section{REFERENCES}

Abacioglu N, Tunctan B, Akbulut E, Cakici I. Participation of the components of L-arginine/nitric oxide/cGMP cascade by chemicallyinduced abdominal constriction in the mouse. Life Sci, 2000; 67(10):112737.

Adeyemi OO, Yemitan OK, Afolabi L. Inhibition of chemically induced inflammation and pain by orally and topically administered leaf extract of Manihot esculenta Crantz in rodents. Journal of Ethnopharmacology, 2008; 119:6-11.

Bhowmick R, Sarwar MS, RahmanDewan SM, Das A, Das B, NasirUddin MM, Islam MS, Islam MS. In vivo analgesic, antipyretic, and anti-inflammatory potential in Swiss albino mice and In Vitro thrombolytic activity of hydroalcoholic extract from Litsea glutinosa leaves. Biological research, 2014; 47:1.

BIGHETTI EJ, HIRUMA-LIMA CA, GRACIOSO JS, BRITO ARS. Anti-inflammatory and Antinociceptive Effects in Rodents of the Essential Oil of Croton cajucara Benth. Journal of Pharmacy and Pharmacology, 1999; 51:1447-1453.

Everts B, Wahrborg P, Hedner T. COX-2-Specific inhibitors-the emergence of a new class of analgesic and anti-inflammatory drugs. Clin Rheumatol, 2000; 19:331-343.

Faisal M, Hossain AI, Rahman S, Jahan R, Rahmatullah M. A preliminary report on oral glucose tolerance and antinociceptive activity tests conducted with methanol extract of Xanthosoma violaceum aerial parts. BMC complementary and alternative medicine,2014; 14:335.

Franzotti E, Santos C, Rodrigues H, Mourao R, Andrade M, Antoniolli A. Anti-inflammatory, analgesic activity and acute toxicity of Sida cordifolia L.(Malva-branca). Journal of Ethnopharmacology, 2000; 72:273-277.

Furie B, Furie BC. Mechanisms of thrombus formation. New England Journal of Medicine, 2008; 359:938-949.

Ghani A. 2003. Medicinal plants of Bangladesh with chemical constituents and uses. Asiatic society of Bangladesh Dhaka.

Ghannadi A, Hajhashemi V, Jafarabadi H. An investigation of the analgesic and anti-inflammatory effects of Nigella sativa seed polyphenols. J Med Food, 2005; 8:488-493.

Gupta M, Mazumder U, Gomathi P, Selvan VT. Antiinflammatory evaluation of leaves of Plumeria acuminata.BMC complementary and alternative medicine, 2006; 6:1.

Gupta S, Ali M, Pillai K, Sarwar Alam M. Evaluation of antiinflammatory activity of some constituents of Lawsonia inermis. FITOTERAPIA-MILANO-, 1993; 64:365-365.

Hinz B, Brune K. [Specific COX-2 inhibitors: prospects of therapy with new analgesic and anti-inflammatory substances]. Wiener klinische Wochenschrift, 1999; 111:103-112.

Hinz B, Brune K. [Specific cyclooxygenase-2 inhibitors. Basis and options of a pharmacotherapeutic concept]. Der Anaesthesist, 2000; 49:964-971.

Hinz B, Brune K. Cyclooxygenase-2-10 years later. Journal of Pharmacology and Experimental Therapeutics, 2002; 300:367-375.

Hiruma-Lima C, Gracioso J, Bighetti E, Robineou LG, Brito AS. The juice of fresh leaves of Boerhaavia diffusa L.(Nyctaginaceae) markedly reduces pain in mice. Journal of Ethnopharmacology, 2000; 71:267-274.

Kennedy JD. Neuropathic pain: molecular complexity underlies continuing unmet medical need. J Med Chem, 2007; 50:2547-2556.

Khan AA, Ashfaq M, Ali MN. 1979. Pharmacognostic studies of selected idigenous plants of pakistan.

Khan SA, Ali A, Zahran SA, Damanhouri G, Azhar E, Qadri I. Unraveling the complex relationship triad between lipids, obesity, and inflammation. Mediators Inflamm, 2014; 502749:28.

Kulkarni S, Jain N, Singh A. Cyclooxygenase isoenzymes and newer therapeutic potential for selective COX-2 inhibitors. Methods Find Exp Clin Pharmacol, 2000; 22:291-298.

Lawson K. Potassium channel activation: a potential therapeutic approach? Pharmacology \& therapeutics, 1996; 70:39-63.
Lu T.-C, Ko Y-Z, Huang H-W, Hung Y-C, Lin Y-C, Peng W-H. Analgesic and anti-inflammatory activities of aqueous extract from Glycine tomentella root in mice. Journal of Ethnopharmacology, 2007; 113:142-148.

Mason RP, Walter MF, Day CA, Jacob RF. A Biological Rationale for the Cardiotoxic Effects of Rofecoxib. In Inflammation in the Pathogenesis of Chronic Diseases. Springer, 2007; 175-190.

Mason RP, Walter MF, McNulty HP, Lockwood SF, Byun J, Day CA, Jacob RF. Rofecoxib increases susceptibility of human LDL and membrane lipids to oxidative damage: a mechanism of cardiotoxicity. Journal of Cardiovascular Pharmacology, 2006; 47:S7S14.

Mohamad AS, Akhtar MN, Khalivulla SI, Perimal EK, Khalid MH, Ong HM, Zareen S, Akira A, Israf DA, Lajis N. Possible Participation of Nitric Oxide/Cyclic Guanosine Monophosphate/Protein Kinase C/ATP-Sensitive K+ Channels Pathway in the Systemic Antinociception of Flavokawin B. Basic \& clinical pharmacology \& toxicology, 2011; 108:400-405.

Momin MAM, Bellah SF, Rahman SMR, Rahman AA, Murshid GMM, Emran TB. Phytopharmacological evaluation of ethanol extract of Sida cordifolia L. roots. Asian Pacific journal of tropical biomedicine, 2014; 4:18-24.

Muccillo-Baisch AL, Parker AG, Cardoso GP, Cezar-Vaz MR, Soares MCF. Evaluation of the analgesic effect of aqueous extract of Brugmansia suaveolens flower in mice: possible mechanism involved. Biological research for nursing,2010; 11:345-350.

Murray CW, Porreca F, Cowan A. Methodological refinements to the mouse paw formalin test: an animal model of tonic pain. Journal of pharmacological methods, 1988; 20:175-186.

Pantzar M, Ljungh Å, Wadström T. Plasminogen binding and activation at the surface of Helicobacter pylori CCUG 17874. Infection and immunity, 1998; 66:4976-4980.

Parker AG, Peraza GG, Sena J, Silva ES, Soares MCF, Vaz MRC, Furlong EB, Muccillo-Baisch AL. Antinociceptive effects of the aqueous extract of Brugmansia suaveolens flowers in mice. Biological research for nursing,2007; 8:234-239.

Perimal EK, Akhtar MN, Mohamad AS, Khalid MH, Ming OH, Khalid S, Tatt LM, Kamaldin MN, Zakaria ZA, Israf DA. Zerumbone-Induced Antinociception: Involvement of the 1-Arginine-Nitric Oxide-cGMP-PKC-K+ ATP Channel Pathways. Basic \& clinical pharmacology \& toxicology, 2011; 108:155-162.

Prasad S, Kashyap RS, Deopujari JY, Purohit HJ, Taori GM, Daginawala HF. Development of an In Vitro model to study clot lysis activity of thrombolytic drugs. Thrombosis Journal,2006; 4:1.

Rahman MA, Sultana R, Emran TB, Islam MS, Rahman MA, Chakma JS, Rashid H-U, Hasan CMM. Effects of organic extracts of six Bangladeshi plants on In Vitro thrombolysis and cytotoxicity. BMC complementary and alternative medicine, 2013; 13:1.

Riedel R, Marrassini C, Anesini C, Gorzalczany S. Antiinflammatory and antinociceptive activity of Urera aurantiaca. Phytother Res, 2015; 29:59-66.

Santos A, Calixto J. Further evidence for the involvement of tachykinin receptor subtypes in formalin and capsaicin models of pain in mice. Neuropeptides, 1997; 31:381-389.

Santos AR,De Campos RO, Miguel OG, Filho VC, Siani AC, Yunes RA, Calixto JB. Antinociceptive properties of extracts of new species of plants of the genus Phyllanthus (Euphorbiaceae). J Ethnopharmacol,2000; 72:229-238.

Süleyman H, Demirezer LÖ, Kuruüzüm A, BanoğluGöçer ZF, Özbakir G, Gepdiremen A. Antiinflammatory effect of the aqueous extract from Rumex patientia L. roots. Journal of Ethnopharmacology, 1999; 65:141-148.

Tjølsen A, Berge O-G, Hunskaar S, Rosland JH, Hole K. The formalin test: an evaluation of the method. Pain,1992; 51:5-17.

Uddin SN,Amin MN, Shahid-Ud-Daula A, Hossain H, Haque MM, Rahman MS, Kader MA. Phytochemical screening and study of antioxidant and analgesic potentials of ethanolic extract of Stephania japonica Linn. Journal of Medicinal Plants Research, 2014; 8:1127-1133. 
Urban MK. COX-2 specific inhibitors offer improved advantages over traditional NSAIDs. Orthopedics, 2000; 23:S761-764.

Watkins LR, Martin D, Ulrich P, Tracey KJ, Maier SF. Evidence for the involvement of spinal cord glia in subcutaneous formalin induced hyperalgesia in the rat. Pain, 1997; 71:225-235.

Watson DJ, Harper SE, Zhao P-L, Quan H, Bolognese JA, Simon TJ. Gastrointestinal tolerability of the selective cyclooxygenase-2 (COX-2) inhibitor rofecoxib compared with nonselective COX-1 and COX-2 inhibitors in osteoarthritis. Archives of Internal Medicine, 2000; 160:2998-3003.

Winter CA, Porter CC. Effect of alterations in side chain upon anti-inflammatory and liver glycogen activities of hydrocortisone esters. Journal of the American Pharmaceutical Association, 1957; 46:515-519.

$\mathrm{Xu}$ JY, Pieper GM, Tseng LF. Activation of a NO-cyclic GMP system by NO donors potentiates beta-endorphin-induced antinociception in the mouse. Pain, 1995; 63:377-383.

Zhang $\mathrm{L}, \mathrm{Hu} \mathrm{J}-\mathrm{J}$, Lin J-W, Fang W-S, Du GH. Antiinflammatory and analgesic effects of ethanol and aqueous extracts of Pterocephalus hookeri (CB Clarke) Höeck. Journal of Ethnopharmacology,2009; 123:510-514.
Zimmermann M. Ethical guidelines for investigations of experimental pain in conscious animals. Pain,1983; 16:109-110.

Zulfiker A, Rahman MM, Hossain MK, Hamid K, Mazumder M, Rana MS. In vivo analgesic activity of ethanolic extracts of two medicinal plants-Scoparia dulcis L. and Ficus racemosa Linn. Biol Med, 2010; 2:42-48.

\section{How to cite this article:}

Nasir Uddin MM, Ahmed S, Kabir MSH, Rahman MS, Emran TB. In vivo analgesic, anti-inflammatory potential in Swiss albino mice and In Vitrothrombolytic activity of hydroalcoholic fruits extract from Daemonorops robusta Warb. J App Pharm Sci, 2017; 7 (01): 104-113. 